\title{
A STUDY ON FUNCTIONAL OUTCOME OF ILIZAROV FIXATION IN THE MANAGEMENT OF INFECTED NONUNION OF LONG BONES
}

\author{
Vellanki Sarath ${ }^{1}$, Chadalavada Venkateswarlu², Basava Narasimha Rao ${ }^{3}$, Ravi Sasanka Sreeram ${ }^{4}$ \\ ${ }^{1}$ Associate Professor, Department of Orthopaedics, Katuri Medical College, Guntur, Andhra Pradesh. \\ ${ }^{2}$ Assistant Professor, Department of Orthopaedics, Katuri Medical College, Guntur, Andhra Pradesh. \\ 3 Professor, Department of Orthopaedics, Katuri Medical College, Guntur, Andhra Pradesh. \\ 4Junior Resident, Department of Orthopaedics, Katuri Medical College, Guntur, Andhra Pradesh.
}

\section{ABSTRACT}

Healing of non-union infected fracture bones like tibia is a challenging one. Ilizarov external ring fixation is the appropriate method. The aim of our study is to evaluate the efficacy of Ilizarov external ring fixator in infected nonunion of bones and functional results in 20 patients and to conduct the study of complications. The age group included in our study were between 30 to 40 years of the 20 cases 17 were males and 3 were females. Of the 20 cases in our study, 14 cases had excellent results, 4 cases had good outcome, 1 patient had fair outcome, 1 cases had poor outcome. The study shows that Ilizarov ring external fixator system is ideal for limb salvage in infected nonunion of long bones.

\section{KEYWORDS}

Ilizarov External Fixator, Distraction Osteogenesis, Infected Nonunion.

HOW TO CITE THIS ARTICLE: Sarath V, Venkateswarlu C, Rao BN, et al. A study on functional outcome of Ilizarov fixation in the management of infected nonunion of long bones. J Evolution Med Dent Sci 2016;5(3): 225-228, DOI: 10.14260/jemds/2016/48

\section{INTRODUCTION}

Nonunion of long bones especially tibia when associated with infection has always been a challenge to orthopaedic surgeons. Bony union is not usually contained until the infection has been eradicated and there are usually coexisting problems of deformity.(1) loss of bone, leg length discrepancy and soft tissue damage. The limb length discrepancy may be treated with extensive operative exposure and technically demanding procedures that do not allow early mobilization and weight bearing. This may be associated with osteoporosis, soft tissue atrophy and persistent infection in the presence of implants. Open cancellous bone grafts have been successfully used to fill tibial defects, some of the best results have been achieved with vascularized free tissue transfer, most patients managed with these methods have multiple operations and a long period of immobilization before consolidation of the grafts. Noninvasive methods are not recommended when osteomyelitis or a bone defect is present despite the excellent results that are often obtained. Some patients undergo an arduous unproductive course of treatment in which the level of disability related to long bone fracture nonunion can counterbalance the benefits of limb salvage procedure.

In 1950's professor G.A. Ilizarov developed his osteosynthesis techniques and treatment combining mechanical and biological factors. Ilizarov technique is based on tension stress effect and distraction histogenesis when a living tissue is distracted in controlled way it produces new tissue of same kind known as regenerate. Ilizarov technique

Financial or Other, Competing Interest: None.

Submission 30-12-2015, Peer Review 31-12-2015,

Acceptance 02-01-2016, Published 11-01-2016.

Corresponding Author:

Dr. Vellanki Sarath,

Associate Professor,

Department of Orthopaedics,

Katuri Medical College,

Andhra Pradesh.

E-mail: drsarathvellanki@rediffmail.com

DOI:10.14260/jemds/2016/48 uses external fixation principles providing multiplanar stability. When applied to nonunion, the Ilizarov principles consist of removal of nonviable or infected tissue, removal of all foreign bodies.(2) or hardware, application of a constructed small wire fixation frame and union through distraction osteogenesis, deangulation and compression. The most important principle and distinct advantage of Ilizarov method.(3) is active use of limb to restore physiologic function, reconstruction of complex nonunions may take as long as 6 months and during this time the fixation supports the extremity and simultaneously allows the patient to work and be active. This study is conducted to report the results of the use of this technique for treatment of infected nonunion of long bones and the study of complications encountered during the treatment.

\section{MATERIALS AND METHODS}

Twenty patients who attended our institution between August 2012 and September 2014 with infected nonunion of long bones were included in our study. All pathological fractures and patients treated with other uniplanar external fixators.(4) were excluded from the study. All the patients were thoroughly evaluated preoperatively. Patients were explained about the procedure and the postoperative care needed and duration of treatment. Preoperative planning was done according to the site of nonunion and preplanning the site of corticotomy if needed was done as per standard procedure. Under suitable anaesthesia, the limb is prepared and patient is placed on a traction table.

The limb is held in ideal position and the ring construct is placed over the limb in the correct way so that the limb is ideally in the middle of the ring in its whole length. It is placed 2 finger breadths anteriorly and 3 finger breadths posteriorly. The construct is assembled with 2 rings above and 2 rings below the nonunion site, sometimes 3 rings were used. The first and last rings are then fixed to the limb with an Ilizarov wire. 
This will position the entire Ilizarov construct ideally, so these are called reference wires. These wires are place parallel to adjacent joint. All the wires were inserted through safe corridors taking care of neurovascular structures, transfixing as little soft tissue as possible. The rest of the Ilizarov wire and half pins are inserted and fixed as planned till a stable Ilizarov external fixator is applied to the limb. Other surgeries like implant removal, excision of infected non-union, fibular osteotomy or partial fibular excision and corticotomy are done as planned earlier before Ilizarov fixation. Alignment of the nonunion site was confirmed with image intensifiers. Minor adjustments of angulation were corrected by compression on one side with distraction on the other side.

\section{RESULTS}

Our study consists of 20 patients with infected nonunion of long bones treated by Ilizarov ring fixator. The mean age being 39.5 years (20-55 years) with 13 patients in the age group between 30-50 years. In 16 cases tibia was involved and in 4 patients femur was involved with infected nonunion. Majority of the patients had Gustillo Andersen grade 3B compound fractures. Duration of nonunion ranged from 4 months to 10 years (Mean of 7.3 months).

Most of the patients had previous attempts at union with a mean of 1.53 procedures or patient (1 to 3 ). Three patients had 3 procedures; 11 patients had 2 procedures and the remaining patients had 1 procedure. Previous attempts ranged from external fixator application (60\%), flap coverage, bone grafting, plates and screws (15\%). Intramedullary devices (25\%), monofocal osteosynthesis was done in 16 cases. Bifocal osteosynthesis was done in 3 cases and trifocal osteosynthesis was done in 1 case with corticotomy at 2 sites. One case required sequestrectomy at later followup. Of the 20 cases, 6 cases required bone grafting. Fixator readjustment had to be done 5 times and wire tensioning in 2 cases. Average months in fixator was 8 months (5-18 months).

Additional protection ranging from protected weight bearing with crutches TP cast application with pop were used. Average time of union was 7 months. All the cases were followed up for a minimum of 12 weeks after the removal of brace or cast. Followup ranged from 12 weeks to 18 months with an average of 4.2 months. Few patients required surgical intervention while in fixator ranging from fixator readjustment, wire tensioning, removal of the wire. Out of the 20 cases, in 19 case sound union occurred without the need for any other intervention. Three cases required additional protection with a brace for more than 6 weeks.

One tibial nonunion which did not show any union due to extensive soft tissue damage finally went onto below knee amputation. Out of the 3 cases which needed additional protection for more than 6 weeks one had a refracture, which was treated conservatively by cast bracing for 2.5 months. In 6 cases bone grafting was done to augment the union as an additional procedure.

Complete resolution of infection was seen in 19 patients; two patients required sequestrectomy out of which 1 patient had a broken wire within the medullary cavity. Infection was controlled after the removal of broken wire. Five patients had limb length discrepancy of more than $2.5 \mathrm{cms}$. at the end of the procedure 2 patients still had limb length discrepancy of more than $2.5 \mathrm{cms}$ which was treated by heel rise. Angulation correction was done in 2 cases with differential distraction.
Bony and functional results were graded according to ASAMI criteria. Bony results 70\% had excellent outcome, 20\% had good outcome, $5 \%$ had fair outcome and $5 \%$ had poor outcome. Functional results $50 \%$ had excellent outcome, $40 \%$ had good outcome, $5 \%$ had fair outcome and $5 \%$ had poor outcome.

\section{Bone results in present study}

\begin{tabular}{|c|c|c|}
\hline Results & No. of Patients & Percentage \\
\hline Excellent & 14 & $70 \%$ \\
\hline Good & 4 & $20 \%$ \\
\hline Fair & 1 & $5 \%$ \\
\hline Poor & 1 & $5 \%$ \\
\hline \multicolumn{2}{|c|}{ Table 1: Bone Results in Present Study } \\
\hline
\end{tabular}

Functional results in present study

\begin{tabular}{|c|c|c|}
\hline Results & No. of Patients & Percentage \\
\hline Excellent & 10 & $50 \%$ \\
\hline Good & 8 & $40 \%$ \\
\hline Fair & 1 & $5 \%$ \\
\hline Poor & 1 & $5 \%$ \\
\hline \multicolumn{2}{|c|}{ Table 2: Functional Results Present Study } \\
\hline
\end{tabular}

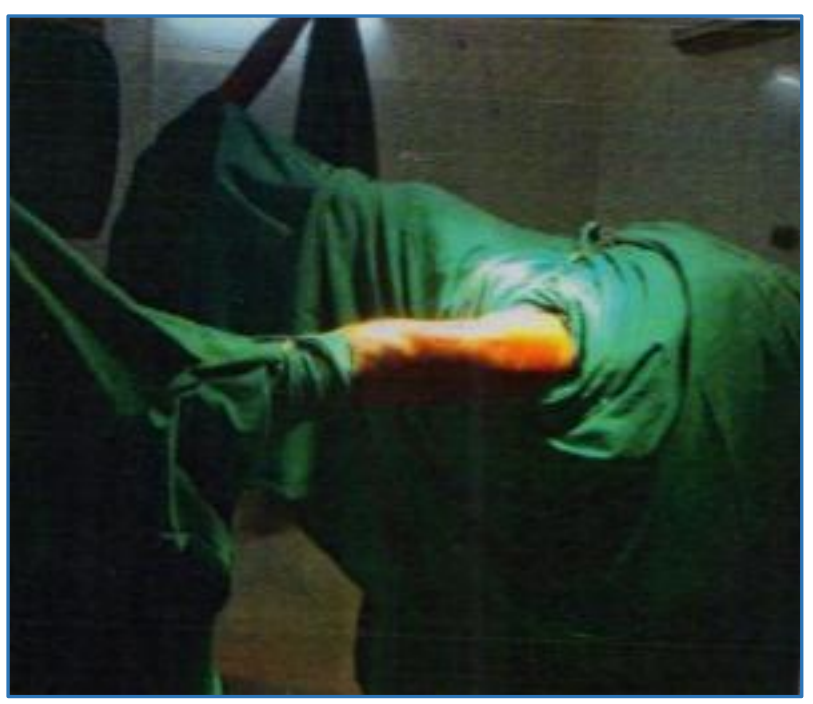

Fig. 1: Positioned in Traction Table and Draped

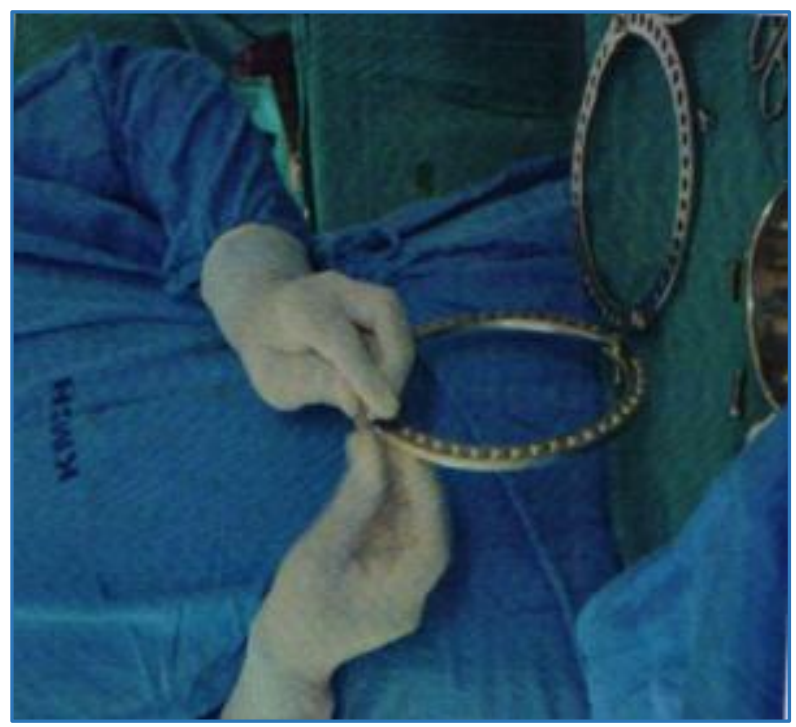

Fig. 2: Assemblage of the Ring 


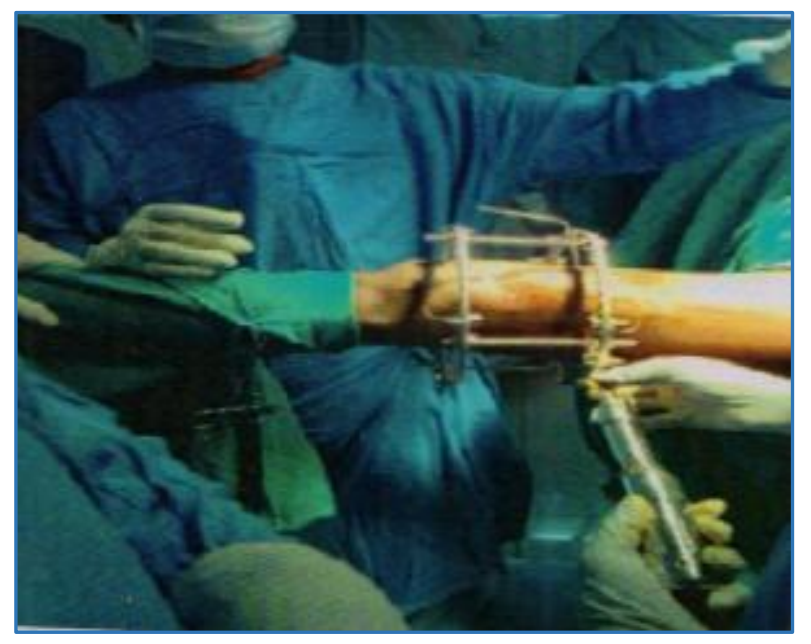

Fig. 3: Tensioning the Wire

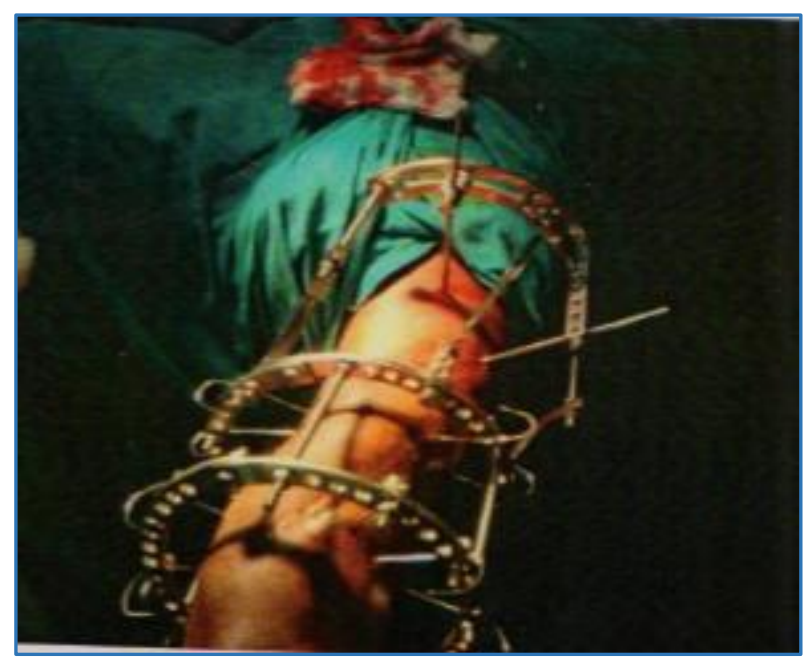

Fig. 4: Fixator applied to Femur

\section{COMPLICATIONS}

The complications are Pain, Joint Stiffness, Muscle Contracture, Wire Site problems, Axial Deviation, Neurological Injury, Vascular Injury, Delayed and Premature Consolidation, Refracture, Joint Subluxation.

\begin{tabular}{|c|c|c|}
\hline PROBLEMS & OBSTACLES & COMPLICATIONS \\
\hline $\begin{array}{c}\text { Pin tract } \\
\text { infection }-10\end{array}$ & $\begin{array}{c}\text { Wire } \\
\text { tensioning-4 }\end{array}$ & Joint stiffness-6 \\
\hline Angulation-2 & $\begin{array}{l}\text { Fixator } \\
\text { realignment-3 }\end{array}$ & $\begin{array}{c}\text { Limb length } \\
\text { discrepancy } \\
>2.5 \mathrm{~cm}-2\end{array}$ \\
\hline Joint stiffness-11 & $\begin{array}{l}\text { Pin tract } \\
\text { infection-3 }\end{array}$ & $\begin{array}{l}\text { Persistent } \\
\text { infection-1 }\end{array}$ \\
\hline $\begin{array}{c}\text { Delayed } \\
\text { Consolidation-2 }\end{array}$ & & $\begin{array}{c}\text { Neurological } \\
\text { deficits-1 }\end{array}$ \\
\hline & & Refracture-1 \\
\hline \multicolumn{3}{|c|}{$\begin{array}{l}\text { Table 3: Problems Obstacles and } \\
\text { Complications of Present Study }\end{array}$} \\
\hline
\end{tabular}

Out of 20 patients, 11 showed loss of Ankle dorsiflexion of more than 15 degrees, after the frame removal. After physiotherapy, 5 gained useful range of movements. One patient had fixed Equinus deformity, one patient with Knee Stiffness.

\section{DISCUSSION}

In India road traffic accidents are common.

\section{Treatment Modalities}

Non-union of long bones can be healed with the Ilizarov fixation. ${ }^{(5)}$ with one of the treatment modalities.

1. Stabilization.

2. Compression.

3. Distraction.

4. Distraction followed by compression.

5. Compression followed by distraction.

6. Bone transport.

7. Corticotomy.

The different treatment modalities that can be used as per Dror Paley Classifications are

Type A 1-Bifocal osteosynthesis

Type A 2-1-Monofocal Osteosynthesis

Type A 2-2-Monofocal Osteosynthesis in distraction and compression with simultaneous correction of deformity with hinges, transverse wires or with olive wires.

Type B 1-single corticotomy with a mobile fragment is transported linearly along the gap by transverse wire fixation. Fibular Osteotomy is not required in this technique.

Type B 2-Bifocal osteosynthesis

Type B 3-It Requires treatment similar to Type 1, but after bone transportation eliminates the gap, distraction must be continued at the site of corticotomy, in order to eliminate shortening of the segment.(6)

Ilizarov states that lack of 1) Stability, 2) Adequate, Vascularity, 3) Axial Alignment, 4) Function.

Pay a major role in the development of non-union. Stability is afforded by application of the apparatus. This provides stable fixation not only at a different level, but also during compression and distraction.

In present study, 20 cases treated by this technique were viewed and majority of the patients are in 30-50 age group. Average age is 39.5 years. Non-union for this study were classified as per Dror-Paley classification of non-unions.(7) which is similar to the studies of Green et al. and Madhusudan et al.

None of the patient had Ilizarov external fixator as the primary modality of the treatment with 2-3 previous surgical interventions with an average of 1.53 interventions. Comparative study by Patel et al. showing 2 interventions; 4 cases had bone gap, corticotomy done in 4 cases, in one case internal bone transport was done and 3 cases external bone transport was done. Latency period is 1 week to 10 days.

\section{COMPARISON}

Functional results comparison

\begin{tabular}{|c|c|c|c|c|}
\hline Study & $\begin{array}{c}\text { Excelle } \\
\text { nt }\end{array}$ & Good & Fair & Poor \\
\hline Drorpaley et al. & $64 \%$ & $28 \%$ & $4 \%$ & $4 \%$ \\
\hline Dendrinos et al. & 25 & $39.2 \%$ & $14.13 \%$ & 22.15 \\
\hline Magdum et al. & $60 \%$ & $32 \%$ & $4 \%$ & $4 \%$ \\
\hline Famanullah et al. & $56.9 \%$ & $31.1 \%$ & $6.9 \%$ & $5.1 \%$ \\
\hline Rose et al. & $16.7 \%$ & $50 \%$ & $0 \%$ & $33.3 \%$ \\
\hline Lalit Miani et al. & $25.7 \%$ & $40 \%$ & $10 \%$ & $24.3 \%$ \\
\hline Cattaneo et al. & $75 \%$ & $0 \%$ & $22 \%$ & $3 \%$ \\
\hline Patil et al. & $44 \%$ & $44 \%$ & $6 \%$ & $6 \%$ \\
\hline Shahid et al. & $50 \%$ & $33 \%$ & $0 \%$ & $0 \%$ \\
\hline Madhusudhan et al. & $5.56 \%$ & $22.22 \%$ & $33.33 \%$ & $38.89 \%$ \\
\hline \multicolumn{7}{|c|}{ Present Study } & $50 \%$ & $40 \%$ & $5 \%$ & $5 \%$ \\
\hline \multicolumn{7}{|c|}{ Table 4: Comparison of Functional Results } \\
\hline
\end{tabular}




\section{CONCLUSION AND SUMMARY}

This llizarov external fixator system is ideal for limb salvaging in the infected non-union of long bones.

- Male patients out-numbered the female with a ratio of 6.33:1.

- The average age of the patient in our study group was 39.3 years.

- $\quad$ Classifying the non-union tibia as per Ilizarov or Dror Paley's method that into stiff and mobile segments was done preoperatively. It is also noted postoperatively that after resection of the nonunion segment all the nonunion sites are mobile.

- $\quad$ All cases in our series were due to road traffic accidents.

- Patients should be thoroughly counselled before the surgery and if any depression occurs during the treatment then adequate psychiatric help should be sought.

- Corticotomy should be done very carefully not to disturb the intramedullary circulation and not to damage to the periosteum

Two finger rules for the ring skin clearance anteriorly and 3 finger breadths posteriorly were sufficient while positioning the rings.

\section{REFERENCES}

1. Abdel-Aal AM. Ilizarov bone transport for massive tibial bone defects. Orthopedics 2006;29:70-74.

2. Ilizarov GA, Ladyaeu UI, The Classic, The replacement of long tubular defects by lengthening distraction osteotomy of one of the fragments. Cli Ortho Rei Res 280:7; 1992.

3. Dagher F, Roukoz S. Compound tibial fractures with bone loss treated by the llizarov technique. J Bone Joint Surg 73-B:316; 1991.

4. Paley D, Fleming B, Catagni $M$, et al. Mechanical evaluation of external fixators used in limb lengthening. Cli Ortho Rel Res:250:50; 1990.

5. Aronson J, Rock L. Leg lengthening, skeletal reconstruction and bone transport with llizarov method. J Bone and Joint surg 79-A:1243; 1997.

6. McHale KA, Ross AE. Treatment of infected tibial nonunions with debridement, antibiotic beads and the Ilizarov method. Mil Med 2004;169:728-734.

7. Naggar L, Chevalley F, Blanc $\mathrm{CH}$ - et al. Treatment of large bone defects with the llizarov technique. J Trauma 34(3):390; 1993. 